\title{
Correction to: Cell-free synthesis of functionally active HSPB5
}

\section{Ryoji Kojima $^{1}$ (D) Keiichi Uchiya ${ }^{2} \cdot$ Hiroyuki Manshio $^{1} \cdot$ Katsuyoshi Masuda $^{3}$}

Published online: 18 February 2020

(C) Cell Stress Society International 2020

\section{Correction to: Cell Stress and Chaperones (2020) https://doi.org/10.1007/s12192-020-01073-5}

In the original publication, the given name of the last author was incorrectly displayed as the name must read: Katsuyoshi Masuda.

In addition, it has come to authors' attention that an inadvertent mistake was made in Table 2, where the entry " 40 WpIRNase inhibitor" should have stated: "40 U/ $\mu$ l RNase inhibitor".

Lastly, the Y-axis of Fig. 6a was distorted so the correct figure is shown here and should be used in place of the previously published figure.

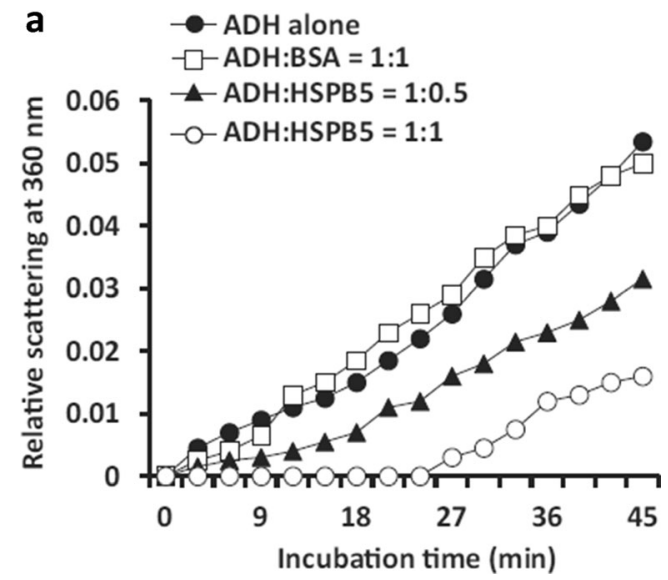

Fig. 6 Inhibition of heat-induced aggregation of ADH and CS by HSPB5 synthesized using the batch and dialysis systems. Light scattering resulting from heat-induced aggregation of $\mathrm{ADH}$ and $\mathrm{CS}$ was assessed by measuring the increase in optical density at $360 \mathrm{~nm}$, as described in the "Materials and Methods." a HSPB5 prepared by the dialysis system exhibited dose-dependent inhibition of the increase in optical density associated with heat-induced aggregation of $\mathrm{ADH}$

Publisher's note Springer Nature remains neutral with regard to jurisdictional claims in published maps and institutional affiliations.

The online version of the original article can be found at https://doi.org/ 10.1007/s12192-020-01073-5

Ryoji Kojima

kojima@meijo-u.ac.jp

1 Laboratory of Analytical Pharmacology, Meijo University, Nagoya 468-8503, Japan

2 Laboratory of Microbiology, Faculty of Pharmacy, Meijo University, Nagoya 468-8503, Japan

3 Suntory Institute for Bioorganic Research, 1-1 Wakayamadai, Shimamoto, Osaka 618-8503, Japan 